\title{
2542. Condition monitoring and fault diagnosis methods for low-speed and heavy-load slewing bearings: a literature review
}

\author{
Fengtao Wang ${ }^{1}$, Chenxi Liu ${ }^{2}$, Wensheng Su${ }^{3}$, Zhigang Xue ${ }^{4}$, Hongkun Li ${ }^{5}$, Qingkai Han ${ }^{6}$

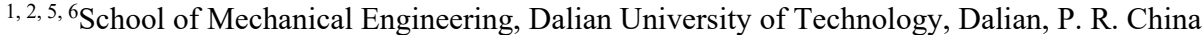 \\ ${ }^{3,4}$ Wuxi Branch, Jiangsu Province Special Equipment Safety Supervision Inspection Institute, \\ Wuxi, P. R. China \\ ${ }^{2}$ Corresponding author

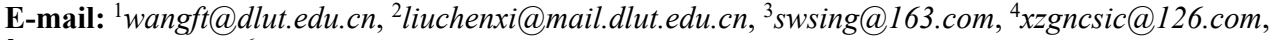 \\ 5lihk@dlut.edu.cn, ${ }^{6}$ hanqingkai@dlut.edu.cn
}

Received 10 April 2017; received in revised form 26 April 2017; accepted 1 May 2017

DOI https://doi.org/10.21595/jve.2017.18454

Check for updates

\begin{abstract}
Low-speed and heavy-load slewing bearings are applied broadly for major mechanical equipment. Compared with ordinary bearings, large slewing bearings have complex structures and work in variable environments. In order to increase productivity, reduce maintenance costs, and ensure the safety of people and equipment, it is of great importance to monitor and diagnose faults in real time. This paper aims at providing a state-of-the-art review on methods for condition monitoring and fault diagnosis of low-speed and heavy-load slewing bearings, including methods based on vibration analysis, acoustic emission technique, oil condition and temperature variation. Additionally, this paper discusses advantages and disadvantages of different methods. Finally, the current needs and challenges are presented to provide a reference for future research.
\end{abstract}

Keywords: large slewing bearings, low-speed, heavy-load, condition monitoring, fault diagnosis.

\section{Introduction}

Low-speed and heavy-load slewing bearings are a subgroup of rolling element bearings that have been developed for nearly four decades. These bearings are commonly used in hoisting and conveying machines [1-3], material processing machines, harbor machines [4, 5], metallurgical machines [6,7], wind power generation [8-13], medical facilities [14, 15], radars and missile launchers [16]. Because of the influence of multiple indexes on the process of design, manufacture, assembly, and use, large slewing bearings are typically to break down. The rotational speed of a large slewing bearing usually ranges from $0.1 \mathrm{rpm}$ to $5 \mathrm{rpm} \mathrm{[17]} \mathrm{and} \mathrm{the} \mathrm{load-bearing}$ capacity is high in a complex working condition. In order to keep productive progress smooth and prevent unplanned downtime, it is necessary to monitor the condition and diagnose fault of slewing bearings in a timely manner.

With the improvement of science and technology and the progress of human society, scientific or production accidents tend to be more unexpected and potentially catastrophic [18-20]. Therefore, safety problems attract more and more attention. The safety tests and online health monitoring of machines are important measures to guarantee the safe service of major equipment [21]. These safety tests utilize physical or chemical methods to obtain structural fault information and determine the safety status. Online health monitoring uses sensor, data acquisition, and network technology to obtain the functional health information of machines and determine anomaly information for subsequent processing. In recent years, heavy and large-size equipment has been the major pillar of the national economy. Thus, methods for condition monitoring and fault diagnosis have always been a focus of attention and study. As the importance of structural health monitoring (SHM) [22-24] has become better recognized, the methods are further developed.

This monitoring can prevent accidents and may decrease personal and property loss. The differences between large slewing bearings and ordinary rolling element bearings are size and shape and also structure and function. The large slewing bearings enable the relative rotation of 
two structural parts [25] and have applications in a wide range of machines. If condition monitoring and fault diagnosis are not available in the early stages of the bearing damage development, it is difficult to avoid economic loss caused by suspending production necessary to ensure personal safety. Large slewing bearings tend to be used in heavy and complex machines, so any faults with these bearing may damage the machines. The maintenance cycle of these machines is fairly long, which can additionally seriously affect the production efficiency and profits. Therefore, condition monitoring and fault diagnosis to determine incipient fault of large slewing bearings have strong practicality. Additionally, the monitoring can promote development of a more modern equipment manufacturing industry and enhance the commodity competitive power of major products and facilities. The working characteristics of large slewing bearings include heavy load, low speed, and intermittent movement. Considering the differences in material property in manufacturing process, dimensional coordination in the assembling process, and loading conditions in the usage process, the time of failure can vary significantly even for the same type of slewing bearings. Therefore, condition monitoring and fault diagnosis can ensure the operational reliability of major equipment. The fault information will be analyzed to determine the cause of failure and can feed back to manufacturers, allowing them to improve the quality of products. Since the 1970s, low-speed and heavy-load slewing bearings have been well studied by many scholars and industries successively. This research area has received more and more attention over time. Taking WEB OF SCIENCE ${ }^{\mathrm{TM}}$ as the retrieval source, Fig. 1 presents the number of published articles relating to slewing bearings.

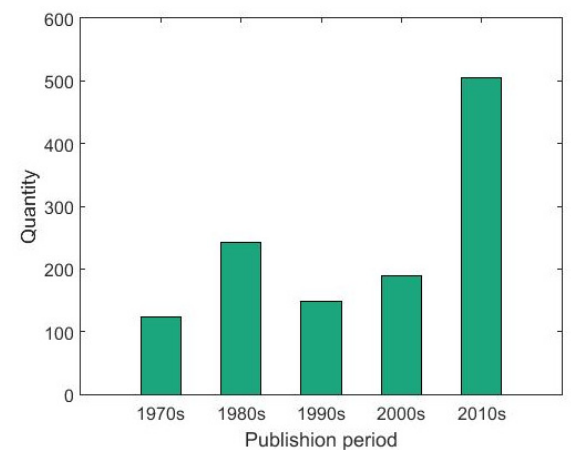

Fig. 1. The number of published articles relating to large slewing bearings

The article is organized as follows. Section 2 presents the structural features and the main faults of large slewing bearings. Section 3 presents the basic introduction of the methods of condition monitoring and fault diagnosis for large slewing bearings. Section 4 presents and compares the methods in detail. Section 5 discusses the current needs and challenges of the methods. Finally, conclusions are drawn in Section 6.

\section{The structural features and the main faults of large slewing bearings}

\subsection{The structural features of large slewing bearings}

Large slewing bearings are "the joints of machines" and can simultaneously support axial loads, radial loads, and overturning moment [26], allowing these bearings to work for many functions including supporting, rotation, transmission, and fixation. The rolling elements of typical slewing bearings with gears in the inner or outer rings are balls or rollers. Different organizations, such as the Ministry of Industry and Information Technology of the People's Republic of China and the American National Standards Institute, classify large slewing bearings into different types. Each type of large slewing bearings is applied in different fields. In general, according to the number of rows, large slewing bearings (with internal gears) can be divided into three categories (see Fig. 2). 


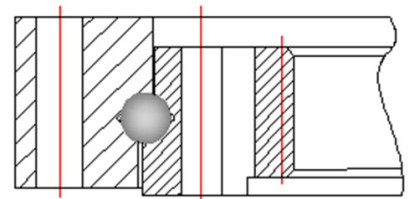

a) Single-row slewing bearing

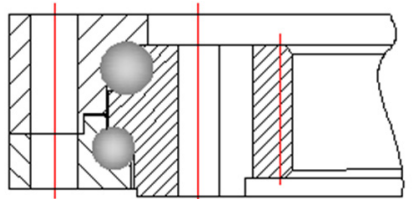

b) Double-row slewing bearing

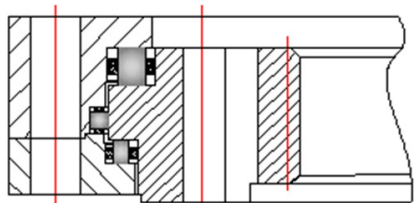

c) Three-row slewing bearing

Fig. 2. Classification of large slewing bearings (with internal gears)

\subsection{The main faults of large slewing bearings}

The structure of low-speed and heavy-load slewing bearings are more complex than rolling element bearings. As shown in Fig. 1, the large slewing bearing, taking the three-row slewing bearing for example, consists of an outer ring, inner ring, rolling elements, isolation blocks, connecting bolts, and other components [25]. Fig. 3 presents the typical faults positions. According to the different positions, the main faults of large slewing bearings are shown in Table 1.

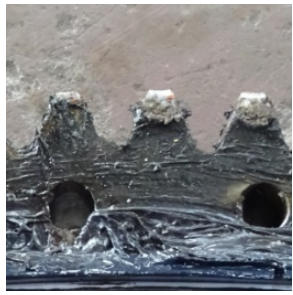

a) Gear teeth

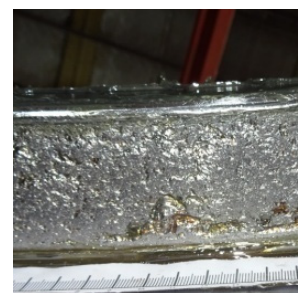

b) Raceway

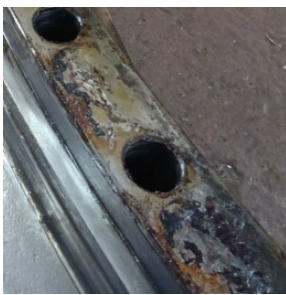

c) Outer/inner ring

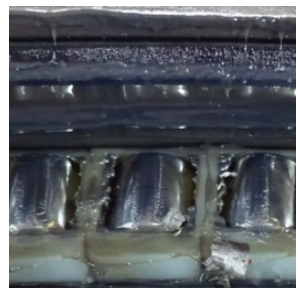

d) Rolling elements

Fig. 3. The typical faults positions

Table 1. The main faults of three-row roller slewing bearings with inner gears

\begin{tabular}{|c|c|c|}
\hline Location of & Main fault & Main cause \\
\hline \multirow{2}{*}{$\begin{array}{l}\text { Outer/inner } \\
\text { ring }\end{array}$} & $\begin{array}{c}\text { Tooth surface abrasion } \\
\text { or pitting }\end{array}$ & $\begin{array}{c}\text { Abrasive dusts dropping in the meshing area or frequent } \\
\text { braking load impacts [27] }\end{array}$ \\
\hline & $\begin{array}{l}\text { Tooth breakage or } \\
\text { fatigue crack }\end{array}$ & $\begin{array}{l}\text { Frequent load impacts caused by low-speed and heavy-load } \\
\text { operation conditions [28] }\end{array}$ \\
\hline \multirow{5}{*}{$\begin{array}{l}\text { Rolling } \\
\text { element }\end{array}$} & \multirow{3}{*}{ Fatigue flaking } & Alternating load acting on the surface of rolling elements [29] \\
\hline & & $\begin{array}{c}\text { Accumulation of internal energy through dislocations and } \\
\text { microcracks }[30]\end{array}$ \\
\hline & & Poor lubrication [31] \\
\hline & \multirow[b]{2}{*}{ Crack or pitting } & Improper assembly, overload or poor lubrication [32] \\
\hline & & $\begin{array}{l}\text { High intensity of periodic contact load between rolling } \\
\text { elements and raceway leading to fatigue crack growth }[33,34]\end{array}$ \\
\hline \multirow{2}{*}{$\begin{array}{c}\text { Connecting } \\
\text { bolt }\end{array}$} & \multirow{2}{*}{$\begin{array}{l}\text { Fatigue crack or } \\
\text { fracture }\end{array}$} & Fail to prevent loosing [35] \\
\hline & & Alternate stress [36] \\
\hline Sealing ring & Distortion or abrasion & Material aging, plastic deformation or other man-made reasons \\
\hline Oil cup & Leak or blocking & Impurities dropping into the cup, etc \\
\hline
\end{tabular}

\section{The development of condition monitoring and fault diagnosis methods for large slewing bearings}

The research of condition monitoring and fault diagnosis methods can be traced back to the 1960s, originating in the US and spreading throughout the world [37]. Condition monitoring aims at determining the mechanical equipment condition based on the technical status in operation, including determining whether the operation is normal and tracking the abnormal condition for trend prediction. Fault diagnosis aims at analyzing equipment faults by monitoring and analysis 
methods to determine the types and locations of faults. This can reveal the need for equipment repair and improvement to ensure the continued reliability and stability of operation. For large slewing bearings, the methods of condition monitoring and fault diagnosis mainly adopt nondestructive detection technology to monitor the condition of the slewing bearings in real time. From this data, the failure features are exacted and analyzed to determine the types and the locations of the faults and ensure the normal operation of the large slewing bearings. In general, the development of condition monitoring and fault diagnosis for the large slewing bearings can be roughly separated into the following three stages.

\subsection{Stage I. Monitoring and diagnosis based on human experience}

At the start of industrial development, there was no theoretical system of condition monitoring and fault diagnosis. Without professional testing equipment, people usually determined whether the fault occurred or not and fault degree by detecting changes in the external environment of the equipment, including abnormal sound, temperature anomaly, broken teeth, metal particles in oil, oil leakage, and other sensory properties. In this stage, people monitored and diagnosed the condition of the slewing bearings based on their previous experience. Although the methods were comparatively easy, they largely depended on the experience of technicians or scientists, which may easily contribute to low accuracy and misjudgment.

\subsection{Stage II. Monitoring and diagnosis based on measurement equipment}

With the development of measurement techniques and computer software, the US, Japan, and some developed countries in Europe carried out studies on computer condition monitoring and fault diagnosis. These were gradually introduced to the study on condition monitoring and fault diagnosis for large slewing bearings. In 1965, James W. Cooley et al. [38] proposed the fast Fourier transformation (FFT) algorithm. From then on, signal analysis was not confined to time domain analysis but various methods based on simple spectral analysis, such as frequency spectrum, energy spectrum, power spectrum, octave spectrum, cepstrum, and time-frequency spectrum have been developed [25, 39-41]. With the development of improved sensor devices and the improvement of the software development technology, the methods of monitoring and diagnosis are no longer highly dependent on human senses and subjective experience, which greatly improved the efficiency and accuracy of signal analysis.

\subsection{Stage III. Intelligent monitoring and diagnosis system based on big data}

Since the 1980s, with the development of computer communication technology and artificial intelligence technology, methods for condition monitoring and fault diagnosis have gradually become more systematized and integrated. The intelligent system can collect information more effectively, extract features more accurately, and analyze the data more quickly. The study of machine learning to obtain information processing technology in diagnosing machine faults is presented in [42]. Reference [43] classifies and compares the main research methods of intelligent diagnosis techniques for major equipment.

Study of the methods of condition monitoring and fault diagnosis for large slewing bearings has drawn much attention of designers and users. Currently, the technical standards and criterions of slewing bearings differ in countries and manufacturers. The manufacturers focus on improving design and manufacturing methods to increase remaining life and product competitiveness. The users focus on monitoring the working condition and the running trend of the slewing bearings to minimize the influence of the faults. In this stage, the objects of monitoring and diagnosis are extended from vibration to oil, torque, temperature, and energy loss. The general monitoring and diagnosis process of current methods for low-speed and heavy-load slewing bearings is illustrated in Fig. 4. 


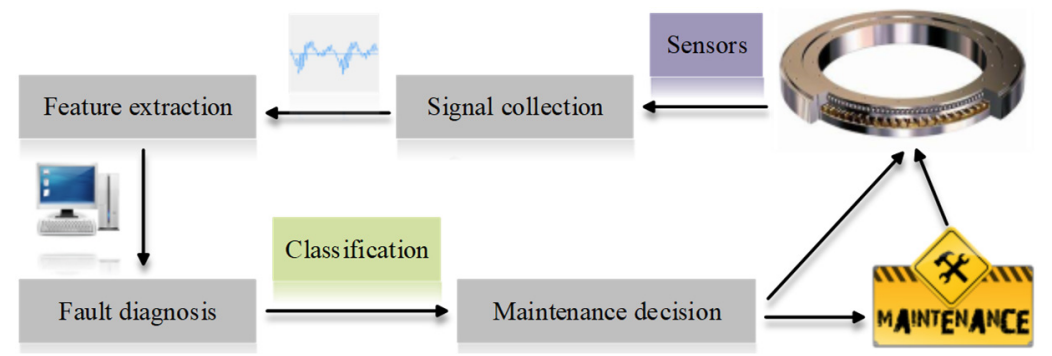

Fig. 4. The general monitoring and diagnosis process

\section{Condition monitoring and fault diagnosis for low-speed and heavy-load slewing bearings}

Recently, there has been an increase in the amount of research into condition monitoring and fault diagnosis methods for large and heavy-load slewing bearings. However, some of the research focuses on the slewing bearings with relative high revolving speed ( $\geq 10 \mathrm{rpm})$ [44]. In many significant application fields, the revolving speed of slewing bearings is lower than $10 \mathrm{rpm}$. In this case, weak low-energy signal is easier merged by strong background noise, which would be harder to extract clear features. The current research of condition monitoring and fault diagnosis methods for low-speed $(<10 \mathrm{rpm})$ and heavy-load slewing bearings has not been fully investigated. To summarize, as for the large slewing bearings with low revolving speed, the current monitoring and diagnosis methods can be roughly divided into four categories: vibration $[45,46]$, acoustic emission (AE) [25, 40, 47], oil condition [48-50], and temperature variation.

\subsection{Condition monitoring and fault diagnosis based on vibration analysis}

Condition monitoring and fault diagnosis methods based on vibration analysis are commonly used, including traditional methods and modern methods [51]. The vibration signals of large slewing bearings collected by the sensors are analyzed for condition monitoring and fault diagnosis. The current methods include amplitude domain, time domain, frequency domain, and time-frequency domain analysis.

\subsubsection{Amplitude domain analysis}

Using statistical analysis to analyze sample values is called amplitude domain analysis. The parameters of amplitude domain analysis mainly include probability density, RMS, kurtosis index, skewness index, peak value, crest index, kurtosis, mean value, and margin index [51]. Amplitude probability density curve of the signal changes when the operation condition of equipment changes, which may be considered as the criterion to diagnose the condition of equipment. Mean value is used to describe the average level of the signal. In general, mean value of vibration signal is about zero. RMS is used to describe energy of signal. The stronger the vibration is, the higher RMS is, which can be used to diagnose abrasion but is not sensitive to early failure. Absolute value of vibration signal's maximum or minimum value is called peak value, which reflects the magnitude of vibration at a certain time. Peak value, kurtosis index, and kurtosis are sensitive to impact but cannot reflect the change of frequency. Considering the stability of the parameters and sensibility during the early stage of failure, people often adopt many parameters to monitor and analyze the faults constantly. For example, by monitoring the variation trend of the vibration signal's peak value, RMS, and kurtosis, the fault development trend of the early stage can be detected and can trigger an alarm if the development value exceeds the set threshold. Meanwhile, people observe and compare the shape and value of the probability density curves of normal signal to abnormal vibration signal to determine whether a fault is starting and to indicate the severity of the faults. The common amplitude domain parameters are presented in Table 2. 
Table 2. The common amplitude domain parameters

\begin{tabular}{|c|c|}
\hline Parameters & Computational equation \\
\hline Mean value & $\mu=\frac{1}{N} \sum_{i=1}^{N} x_{i}, \quad(i=1,2, \cdots, N)$ \\
\hline Mean absolute value & $|\mu|=\frac{1}{N} \sum_{i=1}^{N}\left|x_{i}\right|, \quad(i=1,2, \cdots, N)$ \\
\hline RMS & RMS $=\sqrt{\frac{1}{N} \sum_{i=1}^{N} x_{i}^{2}}$ \\
\hline Peak value & Peak $=$ max $\left(\left|x_{i}\right|\right), \quad(i=1,2, \cdots, N)$ \\
\hline Skewness value & Skewness $=\frac{1}{N} \sum_{i=1}^{N} x_{i}{ }^{3}$ \\
\hline Kurtosis & Kurtosis $=\frac{1}{N} \sum_{i=1}^{N} x_{i}{ }^{4}$ \\
\hline Waveform index & Waveform index $=\frac{\text { RMS }}{|\mu|}$ \\
\hline Impulse index & Impluse index $=\frac{\text { max }\left|x_{i}\right|}{|\mu|}$ \\
\hline Crest index & Crest index $=\frac{\text { max }\left|x_{i}\right|}{\text { RMS }}$ \\
\hline Margin index & Margin index $=\frac{\text { max }\left|x_{i}\right|}{X_{r}}$ \\
\hline Skewness index & Skewness index $=\frac{\text { Skewness }}{S^{3}}$ \\
\hline Kurtosis index & Kurtosis index $=\frac{\text { Kurtosis }}{S^{4}}$ \\
\hline
\end{tabular}

\subsubsection{Time domain analysis}

Determining the operating condition of large slewing bearings by analyzing time domain waveform is called time domain analysis, including correlation analysis, time domain average analysis, and time series analysis. The autocorrelation functions are different from one vibration signal to another, which can be used to determine the operating condition of large slewing bearings. Cross-correlation analysis is usually used to determine the location of fault, the number of vibration sources, and the transmission path of signal. Time domain average analysis is used in signal de-noising to eliminate interference elements of time domain signal. Time series analysis can diagnose the condition of large slewing bearings based on residual errors and coefficients of ARMA model, $\operatorname{AR}(n)$ model, and threshold autoregressive model.

\subsubsection{Frequency domain analysis}

After calculating rolling element, outer ring, and inner ring fault frequencies [52] of large slewing bearings, the vibration signal can be analyzed in frequency domain to determine the specific faults types and locations through spectrograms. The strong high-frequency noise interferes with the real measured signals so as to easily overwhelm low-energy impact signals. When the large slewing bearings faults occur, shock pulses are excited when the fault points contact other components. The broad band shock pulses can excite high-frequency vibration of a variety of equipment and the base, which makes it difficult to directly identify the characteristic frequencies using time domain and frequency domain analysis. Resonance demodulation 
technology developed from vibration testing-analysis technology [53]. According to the running condition of large slewing bearings, a certain period of high-frequency natural vibration signal can be taken as the research subject. The natural vibration can be separated though a band-pass filter, which center frequency equals to natural frequency. Then, through the envelope detector, the high-frequency vibration component is eliminated and a low-frequency envelope signal is obtained that contains fault information. Finally, spectral analysis of this envelope signal can diagnose the faults of large slewing bearings [54].

\subsubsection{Time-frequency domain analysis}

Using spectral analysis alone to deal with large slewing bearings' fault signal does not include the time-varying characteristics. Time and frequency domain analysis can describe two-dimensional distribution information of the time domain and frequency domain, allowing the characterization of local features. Time-frequency domain analysis includes Gabor Transform, short-time Fourier transform, wavelet time-frequency analysis, HHT time-frequency analysis, and ensemble empirical mode decomposition (EEMD).

Many condition monitoring and fault diagnosis studies of large slewing bearings have been conducted. Table 3 lists and analyzes the current methods based on vibration analysis. Although the methods are fully developed, most are based on theoretical models or specimens. Thus, the mathematic models and accuracy need further improvement to meet the actual operation conditions of the large slewing bearings. Based on the methods presented in Table 3, Table 4 further presents the characteristics in terms of amplitude domain analysis, time domain analysis, frequency domain analysis, and time-frequency domain analysis.

Table 3. A summary of current condition monitoring and fault diagnosis methods for low-speed and heavy-load slewing bearings based on vibration

\begin{tabular}{|c|c|c|}
\hline Equipment & Research methods & Results analysis \\
\hline \multirow{4}{*}{$\begin{array}{l}\text { Stacker- } \\
\text { reclaimer }\end{array}$} & Resonance demodulation [53] & $\begin{array}{c}\text { By removing high-frequency component in vibration } \\
\text { signal, low-frequency fault component could be extracted. }\end{array}$ \\
\hline & $\begin{array}{l}\text { Largest Lyapunov exponent } \\
\text { (LLE) algorithm [54] }\end{array}$ & $\begin{array}{l}\text { As a feature extraction method for large slewing bearings, } \\
\text { the LLE algorithm was more effectively than time domain } \\
\text { analysis method and empirical mode decomposition } \\
\text { (EMD). }\end{array}$ \\
\hline & Circular domain analysis [55] & $\begin{array}{c}\text { Some of the circular domain features could potentially } \\
\text { identify the faults of larges slewing bearings at the early } \\
\text { stage and this method was compared with time domain } \\
\text { analysis and EMD to explain its better effect in extracting } \\
\text { fault features from background noise. }\end{array}$ \\
\hline & EMD/EEMD [56] & $\begin{array}{l}\text { The EMD and EEMD method had better effects in } \\
\text { identifying fault frequencies than FFT. }\end{array}$ \\
\hline \multirow{3}{*}{$\begin{array}{l}\text { Engineering } \\
\text { machine }\end{array}$} & $\begin{array}{l}\text { Wavelet decomposition and } \\
\text { energy spectrum [57] }\end{array}$ & $\begin{array}{c}\text { The vibration signal of large slewing bearing was } \\
\text { decomposed into different frequency bands by wavelet } \\
\text { decomposition. The low frequency band spectrum was } \\
\text { selected and analyzed to diagnose the fault combined with } \\
\text { the method of energy spectrum analysis, which was proved } \\
\text { to be more accurate and reliable than single wavelet } \\
\text { spectrum analysis. }\end{array}$ \\
\hline & $\begin{array}{c}\text { Bispectrum analysis and support } \\
\text { vector machine (SVM) [58] }\end{array}$ & $\begin{array}{l}\text { The feature vector of weak signal was extracted by } \\
\text { bispectrum analysis and the four kinds of faults were } \\
\text { classified and identified by SVM. The precision of this } \\
\text { method needed to be further improved. }\end{array}$ \\
\hline & \begin{tabular}{|c|} 
Multi-scale principal component \\
analysis (MSPCA) and EEMD \\
{$[59]$}
\end{tabular} & $\begin{array}{c}\text { The vibration signal of slewing bearing was decomposed } \\
\text { and reconstructed to obtain better denoising effect and } \\
\text { higher noise ratio. }\end{array}$ \\
\hline
\end{tabular}




\begin{tabular}{|c|c|c|}
\hline Crane & Vibration energy analysis [60] & $\begin{array}{l}\text { The vibration value directly reflected internal vibration } \\
\text { condition of large slewing bearing. }\end{array}$ \\
\hline \multirow{2}{*}{ Excavator } & $\begin{array}{l}\text { wavelet analysis, Hilbert } \\
\text { transform and zoom spectrum } \\
\text { analysis }[61,62]\end{array}$ & $\begin{array}{l}\text { The vibration signal of slewing bearing was decomposed } \\
\text { and reconstructed by using wavelet theory. The } \\
\text { characteristic frequency of fault was extracted by using } \\
\text { Hilbert transform and zoom spectrum analysis. }\end{array}$ \\
\hline & $\begin{array}{l}\text { Wavelet theory and } \\
\text { chaotic oscillator detection } \\
\text { method [63] }\end{array}$ & $\begin{array}{l}\text { The vibration signal was analyzed by wavelet } \\
\text { decomposition and Hilbert spectrum analysis. The chaotic } \\
\text { system, which is sensitive to weak signal and immunes to } \\
\text { the noise, could effectively detect the weak fault signal. }\end{array}$ \\
\hline \multirow{3}{*}{ Wind turbine } & Bispectrum analysis [64] & $\begin{array}{l}\text { The fault frequencies of large slewing bearing were } \\
\text { extracted and identified from background noise by using } \\
\text { bispectrum analysis. }\end{array}$ \\
\hline & $\begin{array}{l}\text { EMD and independent } \\
\text { component analysis (ICA) [65] }\end{array}$ & $\begin{array}{l}\text { The source signal of large slewing bearing was separated } \\
\text { by blind source separation method based on EMD and } \\
\text { ICA. The fault frequency could be extracted accurately, } \\
\text { which provided an effective method to solve } \\
\text { underdetermined blind separation problem. }\end{array}$ \\
\hline & $\begin{array}{l}\text { Autocorrelation denoising and } \\
\text { principal component analysis } \\
\text { (PCA) [66] }\end{array}$ & $\begin{array}{l}\text { Autocorrelation analysis was used for denoising and PCA } \\
\text { was used for identifying normal and fault condition. The } \\
\text { fault type of large slewing bearing could be identified by } \\
\text { Hilbert envelope demodulation. }\end{array}$ \\
\hline
\end{tabular}

Table 4. Methods comparison

\begin{tabular}{|c|c|c|}
\hline $\begin{array}{l}\text { Analysis } \\
\text { methods }\end{array}$ & Advantages & Disadvantages \\
\hline $\begin{array}{l}\text { Amplitude } \\
\text { domain } \\
\text { analysis }\end{array}$ & $\begin{array}{l}\text { The parameters are usually easy to calculate and can } \\
\text { be used to preliminary determine the faults of large } \\
\text { slewing bearings compared with the parameters of } \\
\text { normal slewing bearings. }\end{array}$ & $\begin{array}{l}\text { The location and type of the } \\
\text { fault cannot be diagnosed with } \\
\text { high accuracy and the results } \\
\text { cannot be presented visually in } \\
\text { comparison with spectrogram. }\end{array}$ \\
\hline $\begin{array}{l}\text { Time } \\
\text { domain } \\
\text { analysis }\end{array}$ & $\begin{array}{l}\text { The relationship between vibration signal } \\
\text { characteristics and time can be visually shown. }\end{array}$ & $\begin{array}{l}\text { Because low-frequency signal } \\
\text { is easy to submerge in } \\
\text { background noise, faults types } \\
\text { and locations are difficult to } \\
\text { find out only using time } \\
\text { domain analysis. }\end{array}$ \\
\hline $\begin{array}{l}\text { Frequency } \\
\text { domain } \\
\text { analysis }\end{array}$ & Faults types and locations can be determined. & $\begin{array}{l}\text { FFT is limited in analyzing } \\
\text { measured signals which are } \\
\text { generally non-stationary } \\
\text { signals. Besides, time varying } \\
\text { characteristic cannot be } \\
\text { obtained from spectrogram due } \\
\text { to FFT overall characteristic. }\end{array}$ \\
\hline $\begin{array}{l}\text { Time and } \\
\text { frequency } \\
\text { domain } \\
\text { analysis }\end{array}$ & $\begin{array}{l}\text { The current time and frequency domain analysis for } \\
\text { large slewing bearings includes wavelet Transform, } \\
\text { EMD and EEMD. The method of wavelet Transform } \\
\text { has multiresolution characteristics. On the one hand, } \\
\text { the vibration signal can be analyzed in time- } \\
\text { frequency scale. On the other hand, the energy } \\
\text { feature of different frequency bands can be extracted. } \\
\text { The methods of EMD and EEMD are signal } \\
\text { decomposition methods, which can decompose and } \\
\text { reconstruct signal adaptively. Combining with other } \\
\text { time and frequency domain analysis methods, the } \\
\text { weak low-frequency fault feature can be extracted } \\
\text { from strong background noise to realize denosing. }\end{array}$ & $\begin{array}{l}\text { As for wavelet Transform, the } \\
\text { study on choosing optimal } \\
\text { wavelet basis function, } \\
\text { decomposition level and } \\
\text { threshold is insufficient, which } \\
\text { cannot be selected } \\
\text { intelligently. } \\
\text { The problems of frequency } \\
\text { aliasing and marginal effect of } \\
\text { EMD and EEMD have not } \\
\text { been eliminated thoroughly. }\end{array}$ \\
\hline
\end{tabular}




\subsection{Condition monitoring and fault diagnosis based on AE technique}

Structure damage identification is one of the main studies of SHM and condition assessment [67]. The measured vibration signal data are collected by sensors. But this is not the original vibration of large slewing bearings but the re-vibration. Stress and strain are the starting points to research elastic medium movement rule and wave theory [68]. The main methods of condition monitoring and fault diagnosis based on stress and strain include AE technique. AE refers to a physical phenomenon where the object under deformation or external effects rapidly releases elastic energy to generate transient a stress wave [69]. AE is sensitive to the formation of defections, which can monitor the overall development process of the internal structure damage continuously. Meanwhile, the advantages of AE technique can solve three categories of problems in structure damage identification, including whether the fault occurs or not, the location of the fault and the damage degree of the structure. The large slewing bearings always operate under alternate loading conditions. The fault degree varies according to the fault location and stress state, so the operating condition of the large slewing bearings can be monitored online and determined. AE technique is mainly used for monitoring surface fatigue cracks, fatigue failure, and exterior wear of machine parts. Many comparative studies of methods based on vibration and methods based on stress and strain have been published, which show the superiority for the monitoring of low energy and low frequency signal. The studies of condition monitoring and fault diagnosis methods for the large slewing bearings (rotation speed: $\leq 10 \mathrm{rpm}$ ) based on AE technique are presented in Table 5.

Table 5. Methods comparison

\begin{tabular}{|c|c|c|c|}
\hline Research object & $\begin{array}{c}\text { Rotation } \\
\text { speed }\end{array}$ & $\begin{array}{c}\text { Axial } \\
\text { loading }\end{array}$ & Method \\
\hline $\begin{array}{l}\text { Outer ring raceway } \\
\text { fatigue failure [25] }\end{array}$ & $8 \mathrm{rpm}$ & $480 \mathrm{kN}$ & $\begin{array}{l}\text { The combination method of independent component analysis } \\
\text { multivariate monitoring method, EEMD and envelope analysis } \\
\text { (EA) could extract fault information of slewing bearing. }\end{array}$ \\
\hline $\begin{array}{l}\text { Inner ring raceway } \\
\text { fatigue failure [40] }\end{array}$ & $8 \mathrm{rpm}$ & $550 \mathrm{kN}$ & $\begin{array}{l}\text { The combination method of PCA multivariate monitoring } \\
\text { method, EEMD and EA could extract fault information of } \\
\text { slewing bearing. }\end{array}$ \\
\hline $\begin{array}{l}\text { Inner raceway, outer } \\
\text { raceway and rolling } \\
\text { element abrasion }[44] \\
\end{array}$ & $1 \mathrm{rpm}$ & $810 \mathrm{kN}$ & $\begin{array}{l}\text { Using LLE algorithm in analyzing AE signal to extract fault } \\
\text { feature had better effect than using AE hit parameters. The } \\
\text { method needed further verification in lower rotation speed. }\end{array}$ \\
\hline $\begin{array}{l}\text { Inner raceway, outer } \\
\text { raceway and rolling } \\
\text { element abrasion [56] }\end{array}$ & $1 \mathrm{rpm}$ & $810 \mathrm{kN}$ & $\begin{array}{l}\text { The EMD and EEMD method had better effects in identifying } \\
\text { fault frequencies of large slewing bearing than FFT. }\end{array}$ \\
\hline $\begin{array}{l}\text { Inner ring raceway } \\
\text { fatigue failure [70] }\end{array}$ & $8 \mathrm{rpm}$ & $550 \mathrm{kN}$ & $\begin{array}{l}\text { The combination method of kernel principal component } \\
\text { analysis (KPCA) non-linear multivariate monitoring method, } \\
\text { EEMD and EA could extract fault information of slewing } \\
\text { bearing. Compared with linear PCA method, no-linear KPCA } \\
\text { method could better meet the need of analyzing non-linearly } \\
\text { correlated signal of large slewing bearing. }\end{array}$ \\
\hline $\begin{array}{l}\text { Outer raceway and } \\
\text { rolling element } \\
\text { abrasion [71] }\end{array}$ & $\begin{array}{c}1,2 \text { or } 3 \\
\mathrm{rpm}\end{array} \mid$ & $86.24 \mathrm{kN}$ & $\begin{array}{l}\text { The parameter distribution, parameter correlation and } \\
\text { frequency spectrum of AE signal had been analyzed and } \\
\text { compared between slewing bearings with and without defect, } \\
\text { which changed with the variation of rotation speed and } \\
\text { loading. }\end{array}$ \\
\hline $\begin{array}{l}\text { Outer raceway and } \\
\text { rolling element } \\
\text { abrasion [72] }\end{array}$ & $\begin{array}{l}1.07 \text { or } \\
2.73 \\
\text { rpm }\end{array}$ & $86.24 \mathrm{kN}$ & $\begin{array}{l}\text { The fault features of outer raceway and rolling element } \\
\text { abrasion could be roughly identified by using time-frequency } \\
\text { domain analysis, correlation analysis and wavelet analysis. }\end{array}$ \\
\hline $\begin{array}{l}\text { Raceway fatigue } \\
\text { failure [73] }\end{array}$ & $<5 \mathrm{rpm}$ & $250 \mathrm{kN}$ & $\begin{array}{l}\text { The typical features of amplitude, duration, energy and wave } \\
\text { spectrum could be used to preliminary determine the fault of } \\
\text { slewing bearing. }\end{array}$ \\
\hline
\end{tabular}


Compared with methods of condition monitoring and fault diagnosis based on vibration, methods based on AE technique generally have some advantages, including stronger anti-noise-interference ability, higher sensitivity, and broader frequency response. After subsequent signal processing, the acoustic emission frequency signal is more clear and pure, allowing the identification and determination of the faults, especially in the process of dealing with low-frequency signal. In the current study methods based on AE technique, there are still some problems to be resolved.

1) The studies of condition monitoring and fault diagnosis based on AE technique are generally performed by laboratory simulation. Though this research has certain development in theory, there are still some differences between current studies and real-world conditions.

2) The majority of condition monitoring and fault diagnosis studies based on AE technique are aimed at the faults of artificially damage bearings. For the low-speed and heavy-load slewing bearings, the naturally formed faults and working conditions are complex. Therefore, the research conclusions for ordinary bearings may only be used as references. Besides, the rotation speed set in the experiments is not low enough to meet the real-world conditions, which is needed for further study.

3) The equipment cost of $\mathrm{AE}$ technique is relative high and the alarm accuracy rate needs to be improved.

\subsection{Condition monitoring and fault diagnosis based on oil condition}

When a large slewing bearing is operating, deformation slip happens in the contact area. For this reason, the slewing bearing must be lubricated to decrease frictional resistance. In real world conditions, the large slewing bearings are lubricated by oil and grease. Grease lubrication is used as a seal to prevent impurities from mixing in components and also to avoid oil leakage. Oil lubrication is used to reduce friction, protect against rust, and dissipate heat. When the large slewing bearing rotates, abrasive dusts caused by friction stick together in the oil or grease and continually accumulate in contact areas. Some abrasive dust can be transferred in the lubrication oil, so representative samples of abrasive dusts from the oil can be obtained and used for further qualitative and quantitative analysis. Compared with other condition monitoring and fault diagnosis methods, the methods based on oil condition not only give alarm to stop working but also detect slewing bearing's tribological change [48]. The common methods include spectrometric analysis and ferrographic analysis.

Spectrometric analysis is based on the principle of reflection and refraction. In brief, according to the spectrum differences before and after going passing through the sensors, the particle pollution levels and composition of lubrication oil can be analyzed. Finally, the abrasion of the components, faults locations, and types can be determined. This analysis method is widely used in heavy-duty machinery fields to monitor and diagnose faults, including shipping [74], crawler vehicle [75], and aero-engine [76]. In ferrographic analysis, ferromagnetic wear particles in lubrication oil can be separated by use of a high gradient and a strong magnetic field. The size and compositions of the wear particles are analyzed to determine the locations, types and degree of faults. This analysis method is also widely used in heavy-duty machinery fields to monitor and diagnose faults, including marine ship [77], aircraft [78], and diesel engine [79].

However, ferrographic analysis is suited for ferromagnetic wear particles. For non-iron wear particles, people can analyze the composition and relative content of abrasive dusts based on a combination of spectrometry and ferrographic analysis. In [48], the authors successfully identified the faults of the large slewing bearings in port wheel loaders by using a combination of spectrometric analysis and ferrographic analysis.

\subsection{Condition monitoring and fault diagnosis based on temperature variation}

The surface temperature and temperature field distribution of large slewing bearings vary with 
the change of loading and environment temperature. When the slewing bearings break out with lubrication shortage, the friction and collision caused by relative displacement between components become aggravated. Next, the heat transfer conditions get worse, leading to an increase in temperature compared with normal condition signals. So, monitoring the temperature variation can determine the faults condition, and the temperature signals change slowly and are easily affected by changes in the environmental conditions. Therefore, condition monitoring and fault diagnosis based on temperature variation are usually considered as supplementary means to be combined with other methods to monitor the working condition of large slewing bearings [9].

\section{Current needs and challenges of the studies}

Compared with condition monitoring and fault diagnosis methods for ordinary bearings, there are much fewer studies on low-speed and heavy-load slewing bearings. We present current needs and challenges of the studies from the following aspects.

\subsection{Measuring instruments and measuring points}

Measurement range and arrangement of sensors can influence signal acquisition. The majority of measured signals were collected in the laboratories and one single fault rather than complicated faults is analyzed. A large slewing bearing connects two relative rotating parts and works in complex environment. When the bearing breaks down, more than one kind of fault probably occurs. On the other hand, the faults of slewing bearings studied in current methods were almost artificial damage, which was a little different form naturally formed damage. In general, the accelerometer and AE sensors were placed on the radial surface at an angle of $90^{\circ}$ relative to each other around the ring (see Fig. 5).

In real world operating condition, slewing bearings are sealed in machines and fully lubricated so the sensors are expected to be fix stably. Besides, low-frequency vibration signals are often submerged in strong background noise and the sensors which can collect ultra-low frequency vibration are needed. Thus, people need further study to fix the measure points stably and reduce interference of other signals.

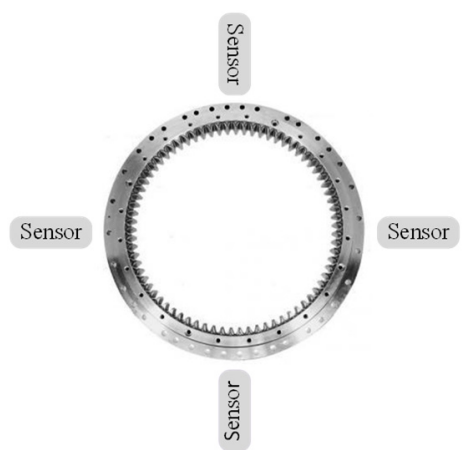

Fig. 5. The arrangement of sensors

\subsection{Integration and intellectualization}

The current methods are still relatively independent and people rarely use a variety of methods to synchronously monitor the faults of large slewing bearings, which are hard to form a complete fault evaluation system. In future, it is necessary to establish integrated system to monitor vibration, AE signals, current, voltage, oil pressure, and temperature, which can help improving stability of the condition monitoring and fault diagnosis system. On the other hand, the automation of current methods is weak and people need to diagnose faults and determine their locations 
regularly. For complex monitoring equipment, the installment and dismantle process are difficult. Therefore, the realization of highly intellectualization and automation is also the direction of future studies.

\subsection{Residual useful life (RUL) prediction}

One of the purposes to monitor condition and diagnose faults is for predicting RUL. RUL prediction is an important guarantee of realizing operation reliability. This research direction is the current hot topic among scholars. Feng Y. et al. [80] proposed a method to predict RUL based on a residual life reliability prediction model. First, a reliability prediction model was built based on Weibull distribution. Then, the Weibull distribution parameters were estimated though an accelerated life test. Finally, the model was verified by experimental slewing bearings life tests. Feng Y. et al. [81] proposed a method to predict the large slewing bearings' RUL based on EEMD-PCA and least squares support vector machine (LSSVM). First, vibration signals of the large slewing bearings were extracted and were then decomposed into several Intrinsic Mode Functions (IMFs) by EEMD. Then, PCA was applied to illustrate the trends of each IMF and some of the IMFs contributing to reveal the degradation process were chosen to reconstruct the signals. Finally, a prediction model based on LSSVM was built and verified to explain the degradation process of the tested slewing bearings. Lu C. et al. [82] proposed a method to predict the large slewing bearings' degradation trend based on LSSVM. First, multi-feature vectors were extracted. Then, PCA was applied to vectors for deducing the degradation process. Finally, a prediction model based on LSSVM was verified its validity by experiment.

Fengtao Wang proposed the main idea of the paper and made guidance in whole process. Chenxi Liu finished the main part of the paper. Wensheng Su assisted the field investigation. Zhigang Xue provided the photos of the paper. Hongkun Li made the theoretical support and suggestions on revision. Qingkai Han made the theoretical support and method guidance.

\section{Conclusions}

Condition monitoring and fault diagnosis methods for low-speed and heavy-load slewing bearings have practical significance. The current methods are mainly applied to the experimental signals and need to be further verified in complex conditions. In future, the factors of technology, economy, and application need to be taken into account to complete condition monitoring, fault diagnosis, and RUL prediction studies as well as improve operational reliability of large slewing bearings.

\section{Acknowledgements}

This work was supported by the National Natural Science Foundation of China (No. 51375067 and No. 71301017).

\section{References}

[1] Jerman B., Podrzaj P., Kramar J. An investigation of slewing-crane dynamics during slewing motion-development and verification of a mathematical model. International Journal of Mechanical Sciences, Vol. 46, 2004, p. 729-750.

[2] Guo J. T., Li S. F. The research of the slewing bearing force balance of the super large lifting equipment. Advanced Materials Research, Vols. 671-674, 2013, p. 888-892.

[3] Maczynski A., Wojciech S. Dynamics of a mobile crane and optimization of the slewing motion of its upper structure. Nonlinear Dynamics, Vol. 32, 2003, p. 259-290.

[4] Chen G., Xiao H. B., Hu L. J., Zhang Y. L. Fault trend identification of slewing bearing of crane. Journal of Wuhan University of Technology, Vol. 28, 2004, p. 223-225.

[5] Nikolakopoulos P., Zavos A. Slew bearings damage detection using Hilbert Huang transformation and acoustic methods. Tribology in Industry, Vol. 37, 2015, p. 170-175. 
[6] Kurashita Y. Development of split type slewing rim bearings. Koyo Engineering Journal Koyo Engineering Journal, Vol. 167, 2005, p. 45-53.

[7] Fitzgerald J. J. Large-diameter slewing ring bearing storage methods: comparisons and cost-effectiveness. AISTech 2012 Iron and Steel Technology Conference and Exposition, Atlanta, United States, 2013, p. 1439-1447.

[8] Śpiewak S. Methodology for calculating the complete static carrying capacity of twin slewing bearing. Mechanism and Machine Theory, Vol. 101, 2016, p. 181-194.

[9] Azevedo H. D. M. D., Araújo A. M., Bouchonneau N. A review of wind turbine bearing condition monitoring: state of the art and challenges. Renewable and Sustainable Energy Reviews, Vol. 56, 2016, p. 368-379.

[10] Wang S. M., Xu M. H. Research on fretting wear of wind turbine slewing bearings. China Mechanical Engineering, Vol. 21, 2010, p. 2430-2433.

[11] Plaza J., Abasolo M., I. Coria, Aguirrebeitia J., Bustos I. F. D. A new finite element approach for the analysis of slewing bearings in wind turbine generators using superelement techniques. Meccanica, Vol. 50, 2015, p. 1623-1633.

[12] Aguirrebeitia J., Plaza J., Abasolo M., Vallejo J. Effect of the preload in the general static load-carrying capacity of four-contact-point slewing bearings for wind turbine generators: theoretical model and finite element calculations. Wind Energy, Vol. 17, 2014, p. 1605-1621.

[13] Mao D. S., Zhang S. H., Guo Z. S. Effect of four point contact slewing bearing groove curvature parameters on the stress state. Advanced Materials Research, Vols. 1032-1011, 2014, p. 1167-1171.

[14] Slew Bearing Application. Medical, ROXXIL.

[15] Moyers M. F., Lesyna W. Isocenter characteristics of an external ring proton gantry. International Journal of Radiation Oncology, Biology, Physics, Vol. 30, 2004, p. 1622-1630.

[16] Slew Bearing Application. Radar Military, ROXXIL.

[17] Glodež S., Potočnik R., Flašker J. Computational model for calculation of static capacity and lifetime of large slewing bearing's raceway. Mechanism and Machine Theory, Vol. 47, 2012, p. 16-30.

[18] Li W. J., Zhang L. B., Liang W. An accident causation analysis and taxonomy (ACAT) model of complex industrial system from both system safety and control theory perspectives. Safety Science, Vol. 92, 2017, p. 94-103.

[19] Sunday A., Adedigba, Faisal K., Yang M. Process accident model considering dependency among contributory indexes. Process Safety and Environmental Protection, Vol. 102, 2016, p. 633-647.

[20] Wang Y. X., Xiang J. W., Markert R., Liang M. Spectral kurtosis for fault detection, diagnosis and prognostics of rotating machines: a review with applications. Mechanical Systems and Signal Processing, Vols. 66-67, 2016, p. 679-698.

[21] Mechanical Engineering Discipline Development Strategy Report (2010 2020). National Natural Science Foundation of Engineering and Materials Science Division, China, 2010.

[22] Glodež S., Potočnik R., Flašker J. Computational model for calculation of static capacity and lifetime of large slewing bearing's raceway. Mechanism and Machine Theory, Vol. 47, 2012, p. 16-30.

[23] Alamdari M. M., Rakotoarivelo T., Khoa N. L. D. A spectral-based clustering for structural health monitoring of the Sydney Harbour Bridge. Mechanical Systems and Signal Processing, Vol. 87, 2017, p. 384-400.

[24] Langone R., Reynders E., Mehrkanoon S., Suykens J. A. K. Automated structural health monitoring based on adaptive kernel spectral clustering. Mechanical Systems and Signal Processing, Vol. 90, 2017, p. 64-78.

[25] Žvokelj M., Zupan S., Prebil I. EEMD-based multiscale ICA method for slewing bearing fault detection and diagnosis. Journal of Sound and Vibration, Vol. 370, 2016, p. 394-423.

[26] Zhang G., Li M. Y., Sun C., Zhang J., Zhang H. L. Load distribution of cross-roller slewing bearing. Applied Mechanics and Materials, Vol. 224, 2012, p. 268-271.

[27] Wang G. X., Tang W. Z., Yang J. X., Yuan J. M. Shock response properties of crane slewing bearing under the condition of revolve braking. Noise and Vibration Control, Vol. 4, 2013, p. 30-34.

[28] Lei Y. G., He Z. J., Lin J., Han D., Kong D. T. Research advances of fault diagnosis technique for planetary gear boxes. Journal of Mechanical Engineering, Vol. 47, 2011, p. 59-67.

[29] Ye Y. X. The research of large-diameter antifriction bearing's trouble mechanism and diagnosing technology of trouble. M.S. dissertation, Department of Mechanical Engineering, Wuhan University of Technology, Wuhan, China, 2005. 
[30] Albert V. K., Andrey A. K., Radoslav K. Mathematical simulation and analysis of rolling contact fatigue damage in rolling bearings. International Journal of Advanced Manufacturing Technology, Vol. 89, 2017, p. 661-664.

[31] Zhu L. G., Zhu X. F. Research on the wear of low speed and high load gears. Chinese Journal of Mechanical Engineering, Vol. 31, 1995, p. 73-78.

[32] Liang J., Chen G. H., Wang X. H. Discussion on fault evolution processes of slewing bearing for crane. Journal of Safety Science and Technology, Vol. 8, 2012, p. 124-128.

[33] Zong H. Y., Wang H., Hong R. J. Dynamic research on single-row slewing bearing with local spalling of inner ring. Advances in Mechanical Engineering, Vol. 8, 2016, p. 1-10.

[34] Potočnik R., Flašker J., Glodež S. Numerical analysis of 3d subsurface crack propagation in large slewing bearing. Proceedings of the ECF18, 2013.

[35] Lin W. M., Zhang Y., Xiang H. Y., Huang J. J. Large pendulum bolt failure analysis and countermeasures. Applied Mechanics and Materials, Vols. 256-259, 2012, p. 600-603.

[36] Qiu M., Yan J. F., Zhao B. H., Chen L. Bai Y. X. A finite-element analysis of the connecting bolts of slewing bearings based on the orthogonal method. Journal of Mechanical Science and Technology, Vol. 26, 2012, p. 883-887.

[37] Li Q. The development of condition monitoring and fault diagnosis on electrical equipment. Electric Power Information Technology, Vol. 7, 2009, p. 12-14.

[38] Cooley J. W., Turkey J. W. An algorithm for the machine calculation of complex Fourier series. Mathematics of Computation, Vol. 19, 1965, p. 297-301.

[39] Mishra C., Samantaray A. K., Chakraborty G. Rolling element bearing fault diagnosis under slow speed operation using wavelet denoising. Measurement, Vol. 107, 2017, p. 77-86.

[40] Žvokelj M., Zupan S., Prebil I. Multivariate and multiscale monitoring of large-size low-speed bearings using ensemble empirical mode decomposition method combined with principal component analysis. Mechanical Systems and Signal Processing, Vol. 24, 2010, p. 1049-1067.

[41] Teng W., Jiang R., Ding X., Liu Y. B., Ma Z. Y. Detection and quantization of bearing fault in direct drive wind turbine via comparative analysis. Shock and Vibration, Vol. 2016, 2016, p. 1-12.

[42] Zhao R. Z., Li C., Zhang Y. Y. Study on fault knowledge processing modes in intelligent diagnosis based on theory of rough set. Journal of Vibration and Shock, Vol. 27, 2007, p. 71-74.

[43] Yang C., Li Y. T. Status quo and development of intelligent diagnostic techniques for mechanical equipment faults. Journal of East China Jiaotong University, Vol. 28, 2011, p. 23-28.

[44] Caesarendra W., Kosasih B., Tieu A. K., Zhu H. T., Moodie C. A. S., Zhu Q. Acoustic emission-based condition monitoring methods: review and application for low speed slew bearing. Mechanical Systems and Signal Processing, Vols. 72-73, 2016, p. 134-159.

[45] Lu C., Chen J., Hong R. J., Feng Y., Li Y. Y. Degradation trend estimation of slewing bearing based on LSSVM model. Mechanical Systems and Signal Processing, Vols. 76-77, 2016, p. 353-366.

[46] Yang F., Huang X. D., Hong R. J., Chen J. Online residual useful life prediction of large-size slewing bearings - A data fusion method. Journal of Central South University, Vol. 24, 2017, p. 114-126.

[47] Chen G. H., Liang J., Wang X. H. TDOA-based location and its correction of acoustic emission source with slewing ring. Journal of South China University of Technology, Vol. 41, 2013, p. 142-146.

[48] Bai X. Q., Xiao H. L., Zhang L. The condition monitoring of large slewing bearing based on oil analysis method. Key Engineering Materials, Vols. 474-476, 2011, p. 716-719.

[49] Liu R. D. Condition monitoring of low-speed and heavily loaded rolling element bearing. Industrial Lubrication and Tribology, Vol. 59, 2007, p. 297-300.

[50] Liu R. D., Ni Z. Condition monitoring of low-speed and heavily loaded rolling element bearing. Lubrication Engineering, Vol. 179, 2006, p. 171-173.

[51] Zhou X. Y., Luo D. F. Research of amplitude-frequency domain parameters analysis for condition detection and fault diagnosis. Research Journal of Applied Sciences, Engineering and Technology, Vol. 4, 2012, p. 3787-3790.

[52] Eschmann P., Hasbargen L., Weigand K. Design and Application of Rolling Bearings. R. Oldenburg, Munich, 1953.

[53] Wang Z. G., Li Y. R., Lu Y. Study on fault diagnosis of the ctoss-rolling bearing in the gyration-support installing of combined bucket-wheel. Journal of Vibration and Shock, Vol. 21, 2002, p. 49-51.

[54] Caesarendra W., Kosasih B., Tieu A. K., Moodie C. A. S. Application of the largest Lyapunov exponent algorithm for feature extraction in low speed slew bearing condition monitoring. Mechanical Systems and Signal Processing, Vols. 50-51, 2015, p. 116-138. 
[55] Caesarendra W., Kosasih B., Tieu A. K., Moodie C. A. S. Circular domain features based condition monitoring for low speed slewing bearing. Mechanical Systems and Signal Processing, Vol. 45, 2014, p. 114-138.

[56] Caesarendra W., Kosasih P. B., Tieu A. K., Moodie C. A. S., Choi B. K. Condition monitoring of naturally damaged slow speed slewing bearing based on ensemble empirical mode decomposition. Journal of Mechanical Science and Technology, Vol. 27, 2013, p. 2263-2262.

[57] Yang J., Chen J., Xu X. T., Hong R. J. Slewing bearing analysis on fault diagnosis based on wavelet and energy fault mode and its application. Journal of Nanjing Tech University, Vol. 37, 2015, p. 134-140.

[58] Chen J., Sun Y. P., Hong R. J., Feng Y. Application of bispectrum analysis and support vector machine in fault diagnosis for slewing bearings. Vol. 5, 2016, p. 53-57.

[59] Yang J., Chen J., Hong R. J., Wang H., Yang F. Research of slew bearing signal de-noising based on multi-scale principal component analysis and EEMD. Journal of Central South University, Vol. 47, 2016, p. 1173-1180.

[60] Chen G., Xiao H. B., Hu L. J., Zhang Y. L. Fault trend identification of slewing bearing of crane. Journal of Wuhan University of Technology, Vol. 28, 2004, p. 223-225.

[61] Guo G. T., Duan. Z. S., Shi L. C., Zhao L. Fault diagnosis method of small excavator rotary bearing. Coal Mine Machinery, Vol. 35, 2014, p. 262-264.

[62] Guo G. T., Duan. Z. S., Shi L. C., Zhao L. Fault diagnosis method of mini excavator slewing bearing. Applied Mechanics and Materials, Vols. 541-542, 2014, p. 544-548.

[63] Zhao L. The Early Weak Signal Detection of Mini Excavator Slewing Bearing Based on Chaotic Oscillator. M.S. Dissertation, Department of Mechanical Engineering, Xi'an University of Architecture and Technology, Xian, China, 2014.

[64] Zhao Y., Chen J., Hong R. J., Feng Y. Application and research in fault diagnosis of slewing bearing based on bispectrum analysis. Machinery Design and Manufacture, Vol. 4, 2016, p. 253-257.

[65] Zhao Y., Chen J., Hong R. J., Feng Y. Application of EMD and ICA in fault diagnosis for slewing bearings. Bearing, Vol. 7, 2015, p. 54-59.

[66] Yang J., Chen J., Hong R. J., Yang F. Application of PCA and autocorrelation envelope analysis in fault diagnosis for slewing bearings. Bearing, Vol. 10, 2014, p. 54-58.

[67] Liu T., Li A. Q., Ding Y. L., Li Z. J., Fei Q. G. Experimental study on structural damage alarming method based on wavelet packet energy spectrum. Journal of Vibration and Shock, Vol. 28, 2009, p. 4-9.

[68] Wang N., Chen C. Z., Sun C. C., Zhou B. Study on fault diagnosis of low-speed rolling bearing using stress waves and wavelet analysis. Journal of Vibration Engineering, Vol. 20, 2007, p. 280-284.

[69] Wang H. Q., Guo Y. W., Yang J. F., Song L. Y., Pan J., Chen P., Yuan H. F. Fault diagnosis based on acoustic emission signal for low speed rolling element bearing. Advanced Materials Research, Vols. 199-200, 2011, p. 1020-1023.

[70] Žvokelj M., Zupan S., Prebil I. Non-linear multivariate and multiscale monitoring and signal denoising strategy using kernel principal component analysis combined with ensemble empirical mode decomposition method. Mechanical Systems and Signal Processing, Vol. 25, 2011, p. 2631-2653.

[71] Jiao Y., Li G. H., Wu Z. W., Chen C., Mi S. Y. Experimental study on acoustic emission detection for low speed heavy duty crane slewing bearing. Springer Proceedings in Physics, Vol. 158, 2015, p. $547-555$.

[72] Li H., Zhao Z. Y., Wu Z. W. Using AE technique to diagnose fault of slewing bearing. China Water Transport, Vol. 13, 2013, p. 309-313.

[73] Wang X. H., Liang J., Li G. H. AE signal feature analysis of portal slewing crane. Lifting the Transport Machinery, Vol. 10, 2014, p. 47-62.

[74] Wei H. J., Wang Z. H., Sun P. T., Yu H. L., Guan D. L., Hu Q. C., Yin F. Study on the characteristic parameter of oil spectrometric analysis. Spectroscopy and Spectral Analysis, Vol. 25, 2005, p. 1125-1127.

[75] Zhang Y. F., Ma B., Zhang J. L., Chen M., Fan Y. H., Li W.C. Study on fault diagnosis of power-shift steering transmission based on spectrometric analysis and SVM. Spectroscopy and Spectral Analysis, Vol. 30, 2010, p. 1158-1590.

[76] Wang H. W., Chen G., Chen L. B., Song K., Li A. A fault monitoring technique for wear of aero-engine rolling bearing. Journal of Aerospace Power, Vol. 29, 2014, p. 2256-2263.

[77] Isaa M. C., Yusoffa N. H. N., Naina H., Yatia M. S. D., Muhammada M. M., Nor I. M. Ferrographic analysis of wear particles of various machinery systems of a commercial marine ship. Procedia Engineering, Vol. 68, 2013, p. 345-351. 
[78] Fan Q. H., Han W. The application of the ferrograph analysis technology in hydraulic system fault analysis for aircraft. Chinese Hydraulics and Pneumatics, Vol. 5, 2007, p. 59-61.

[79] Qin R. X., Bian L., Zhang H. L. The application research of ferrograph analysis in marine diesel engine. China Shiprepair, Vol. 28, 2015, p. 36-39.

[80] Feng Y., Huang X. D., Chen J., Wang H., Hong R. J. Reliability-based residual life prediction of large-size low-speed slewing bearings. Mechanism and Machine Theory, Vol. 81, 2014, p. 94-106.

[81] Feng Y., Huang X. D., Hong R. J., Chen J. Residual useful life prediction of large-size low-speed slewing bearings-a data driven method. Journal of Vibroengineering, Vol. 17, 2015, p. 4164-4178.

[82] Lu C., Chen J., Hong R. J., Feng Y., Li Y. Y. Degradation trend estimation of slewing bearing based on LSSVM model. Mechanical Systems and Signal Processing, Vol. 76, Issue 77, 2016, p. 353-366.

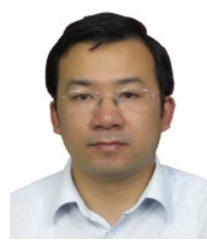

Fengtao Wang received Ph.D. degree in School of Mechanical Engineering from Dalian University of Technology, Dalian, China, in 2003. Now he works at Dalian University of Technology. His current research interests include signal processing, condition monitoring, fault prediction, dynamic characteristics analysis, and pattern recognition.

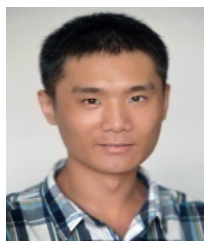

Chenxi Liu now study at Dalian University of Technology, Dalian, China. His current research interests include condition monitoring and fault diagnosis.

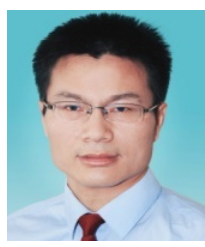

Wensheng Su received Ph.D. degree in School of Mechanical Engineering from Dalian University of Technology, Dalian, China, in 2010. Now he works at Wuxi Branch, Jiangsu Province Special Equipment Safety Supervision Inspection Institute. His current research interests including crane inspection and testing, mechanical equipment fault diagnosis, signal processing and condition monitoring.

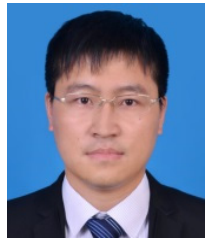

Zhigang Xue received Master degree in Department of Mechanics from Dalian University of Technology, Dalian, China, in 2015. Now he works at Wuxi Branch, Jiangsu Province Special Equipment Safety Supervision Inspection Institute. His current research interests include structural analysis, structural dynamics research, and virtual instruments design.

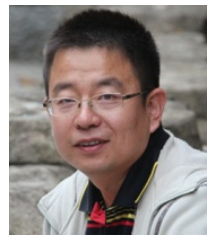

Hongkun Li received Ph.D. degree in School of Mechanical Engineering from Dalian University of Technology, Dalian, China, in 2003. Now he works at Dalian University of Technology. His current research interests include weak signal feature extraction, equipment condition monitoring and operational reliability evaluation, and system vibration and noise control.

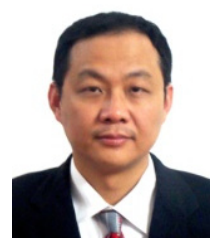

Qingkai Han received Ph.D. degree in School of Mechanical Engineering from Northeastern University, Shenyang, China, in 1996. Now he works at Dalian University of Technology. His current research interests include mechanical dynamics and vibration, fault diagnosis, and advanced damping technology. 